\title{
Degradasi Landskap Hutan dan Pola Konflik Harimau Sumatra Dengan Manusia di Kabupaten Pesisir Selatan
}

\author{
Henzulkifli Rahman ${ }^{1}$, Rizqi Atthoriq Hidayat ${ }^{2}$, dan Adek Hendra Nazar ${ }^{3}$ \\ ${ }^{1,2}$ Program Studi Geografi, Universitas Universitas Negeri Padang \\ ${ }^{3}$ Balai Konservasi Sumberdaya Alam BKSDA, Sumatera Barat \\ ${ }^{3}$ Pasca Sarjana Ilmu Lingkungan, Universitas Andalas \\ e-mail: hendzrahman12@gmail.com
}

\begin{abstract}
ABSTRAK. Harimau Sumatera phantera tigris sumatrae adalah satwa endemik pulau sumatera Sumatera yang saat ini berada red zone atau hewan terancam punah. Banyak faktor penyebab kepunahan, salah satunya adalah deforestasi dan pembukaan lahan untuk kebutuhan manusia menekan lanskap hutan alami yang menjadi habitat spesies ini dan memicu terjadinya konflik satwa. Tujuan penelitian untuk melakukan pemetaan jenis untuk landskap berdasarkan konsep ekologi lanskap pada kawasan hutan, dan melakukan zonasi konflik satwa liar Harimau Sumatra dengan manusia. Metode yang digunakan adalah analisis spasial dengan sistem informasi geografis dan penginderaan jauh dan analisis deskriptif. Data yang digunakan adalah citra satelit sentinel tahun 2020. Riwayat kejadian konflik diperoleh dari BKSDA Provinsi Sumatera Barat data ini dianalisis dengan metode kernel density untuk merepresentasikan zona bahaya konflik. Secara keseluruhan pemanfaatan lahan yang tidak sesuai dengan penunjukkan kawasan hutan dimana yang seharusnya ditutupi oleh landskap hutan akan tetapi pemanfaatanya adalah pertanian lahan kering. Pada kawasan hutan lindung HL luas perkebunan mencapai 3.363 hektar, pada Kawasan Suaka Alam KSA 403 hektar dan pada kawasan TNKS Taman Nasional Kerinci Seblat 3192 Hektar. Dalam kurun waktu satu dekade terjadi 23 kali kejadian konflik harimau dengan manusia. Secara spasial konflik ini terfokus pada wilayah utara Kabupaten Pesisir Selatan, dimana tersebar diantara dua landskap hutan yang terpisah.
\end{abstract}

Kata kunci: ekologi landskap, satwa liar, konflik, harimau Sumatera.

\section{PENDAHULUAN}

Kawasan hutan merupakan suatu area yang ditetapkan sebagai hutan berdasarkan kelompokkelompok tertentu oleh pemerintah Indonesia melalui Kementrian Kehutanan. Kawasan hutan mencakup berbagai fungsi seperti kawasan hutan lindung, kawasan hutan produksi, kawasan hutan produksi terbatas, kawasan hutan produksi konversi, kawasan pelestarian alam, kawasan suaka alam, taman nasional, dan kawasan ekosistem esensial. Dalam kawasan hutan sendiri pemanfaatan penggunaan lahan sangat diatur oleh pemerintah sesuai fungsi penetapannya, maka saat pemanfaatan hutan tidak sama itu dapat disimpulkan bahwasanya tidak sinkron antara pemanfaatan kawasan hutan dengan status yang diakui Negara republic Indonesia. Vegetasi alami berupa hutan merupakan aspek yang sangat penting untuk keberlangsungan hidup satwa liar, pada lanskap hutan akan menampung berbagai siklus kehidupan makluk hidup atau bank biodiversity hingga berfungsi untuk menyimpan karbon dalam mengatasi perubahan iklim (Hidayat et al. 2020, 2021). Akan tetapi ekspansi pemanfaatan lahan terus terjadi sehingga tidak sedikit lahan yang ditutupi vegetasi alami menjadi lahan infrastruktur ataupun kawasan budidaya lainnya (Hanif et al, 2017, 2019). Saat ini tidak sedikit lanskap hutan pada kawasan hutan yang sudah berkurang, sehingga kawasan hutan tidak lagi ditutupi lanskap hutan alami melainkan kawasan budidaya, sehingga semakin menipisnya lanskap alami yang menjadi habitat untuk biodiversity. Perubahan tutupan lahan yang menjadi dasar penilaian lanskap akan mempengaruhi 
konektifitas ekosistem, saat konektifitas ekosistem terganggu maka akan banyak dampak pada kehidupan (Rahman et al. 2020). Pada kasus yang lebih krusial berkurangnya lanskap hutan ini menyebabkan terjadinya konflik satwa liar dengan manusia, diantaranya seperti konflik Gajah Sumatra, harimau Sumatra, Beruang Madu, Macan, dan berbagai jenis satwa dilindungi lainnya. Lanskap.

Harimau Sumatera panthera tigris sumatrae merupakan satu dari enam sub spesies harimau yang masih bertahan hidup hingga saat ini dan hewan endemic pulau Sumatra. Dia memiliki tubuh yang relatif paling kecil dibandingkan semua sub spesies harimau yang hidup saat ini. Warna kulit Harimau Sumatera merupakan yang paling gelap dari seluruh harimau, mulai dari kuning kemerahmerahan hingga oranye tua. Satwa ini masuk dalam status Kritis (www.wwf.or.id, 2012).Harimau Sumatera adalah jenis yang termasuk langka di antara sub-spesies harimau yang masih ada jumlah mereka hanya tinggal sekitar 400-500 ekor (Winardi, Djoko Gunardi, 2009). Habitat alami harimau Sumatera adalah di alam bebas, sepanjang tersedia cukup mangsa dan sumber air, serta terhindar dari berbagai ancaman potensial. Di habitat aslinya, harimau Sumatera terdapat di hutan hujan dataran rendah hingga pegunungan, dengan ketinggian antara $0-3.000$ meter di atas permukaan laut (Ganesa, 2012).

Habitat Harimau Sumatera beranekaragam dari dataran pantai berawa payau dengan tipe vegetasi hutan primer, hutan sekunder, padang rumput. sampai lahan perkebunan dan pertanian masyarakat (Olivia, Eviene Kemala, 2011). Ancaman terbesar terhadap kelestarian Harimau Sumatera adalah aktivitas manusia, terutama konversi kawasan hutan untuk tujuan pembangunan seperti perkebunan, pertambangan, perluasan pemukiman, transmigrasi dan pembangunan infrastruktur lainnya. Selain mengakibatkan fragmentasi habitat, berbagai aktivitas tersebut juga sering memicu konflik antara manusia dan harimau, sehingga menyebabkan korban di kedua belah pihak, bahkan sering berakhir dengan tersingkirnya harimau dari habitatnya (Soehartono, 2007).

Konflik manusia dengan harimau telah lama menjadi masalah serius di lanskap. Dari tahun 1997 hingga tahun 2007, 235 kasus konflik manusia-harimau didokumentasikan di seluruh lanskap, dengan sedikitnya 36 harimau terbunuh atau terluka. Banyak orang terbunuh atau terluka oleh harimau. Sebagai akibatnya, penduduk desa sering berusaha untuk membunuh harimau yang bermasalah, meskipun mereka didorong untuk menghubungi departemen kehutanan untuk mencoba membuat harimau terperangkap hidup dan dipindahkan dari daerah tersebut (World Wildlife Fund, 2010). Riwayat konflik Harimau Sumatera terjadi karena terputusnya konektivitas habitat dan fragmentasi hutan pada habitat harimau, ekspansi lahan yang tidak bisa dikendalikan karena desakan kebutuhan lahan merubah kondisi tutupan lahan seiring bertambahnya jumlah populasi penduduk.

Gambar 1. Dokter hewan dan masyarakat melakukan evakuasi pada harimau yang sudah dibius di Timbulun Aia Tajun, Sumatra Barat. Sumber : tempo.com 2016.

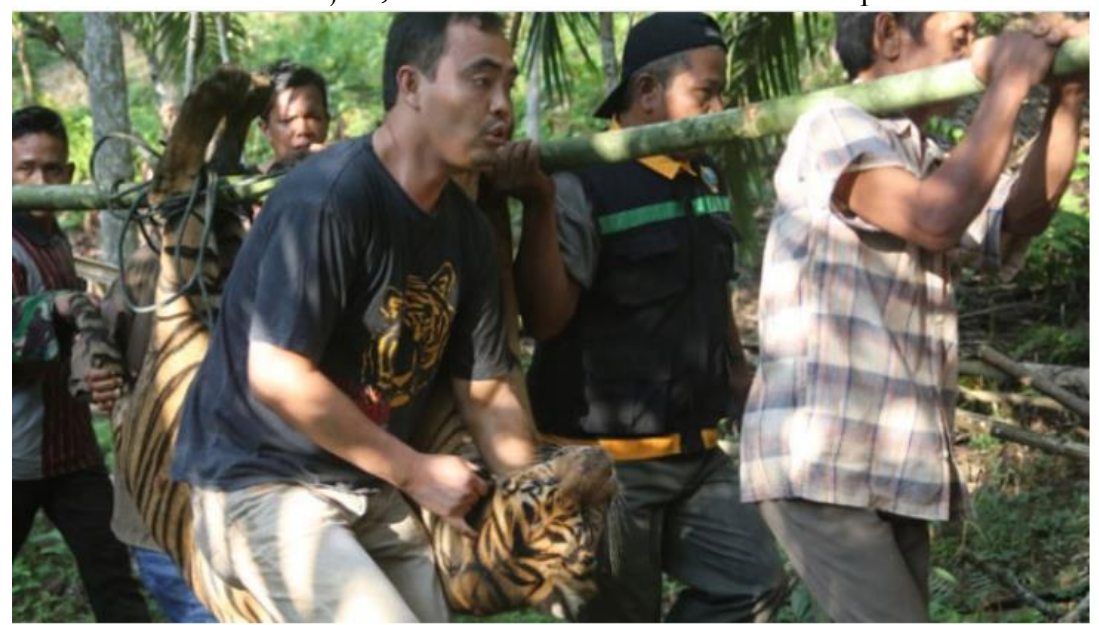

Penelitian berlokasi di kawasan Regional Kabupaten Pesisir Selatan Provinsi Sumatera Barat yang bersinggungan langsung dengan kawasan cagar alam Bukit Barisan, secara astronomis 
terletak di 1000 1' 12,42” BT - 1010 1' 21,87' BT dan 10 15'55,89” LS - 20 16' 52,073” . Penelitian ini bertujuan untuk memonitoring perubahan tutupan lahan dan zonasi bahaya kejadian konflik Harimau Sumatera dari perubahan tutupan terjadinya penekanan habitat yang memicu konflik satwa. Pemetaan pola kejadian konflik berdasarkan intensitas kerapatan titik kejadian konflik yang berguna untuk mengetahui lokasi dengan tingkat bahaya yang paling tinggi ke tingkat bahaya yang paling rendah sesuai menurunnya jarak dari titik kejadian konflik.

\section{METODE}

\subsection{Data}

Dalam penelitian ini digunakan data yaitu citra landsat TM 5 dan OLI 8 bersumber dari website USGS, data riwayat kejadian konflik Harimau Sumatera bersumber dari BKSDA Provinsi Sumatera Barat. Batas administrasi dari website BIG Badan Informasi Geospasial. data tersebut proses dan dianalsis dengan intrepetasi citra pengindraan jauh dan sistem informasi geografis.

\subsection{Analisis Data}

\subsubsection{Klasifikasi Citra Satelit}

Klasifikasi citra dengan algortimta Maximum Likelihood menurut Gao, (2010) menjelaskan landasan berpikir algoritma maximum likelihood, analisis ini menggunakan probabilitas suatu pixel untuk menjadi anggota dari suatu kelas informasi atau label tertentu. Pada tahap analisis ini menggunakan data citra Sentinel 2a untuk mendapatkan peta tutupan lahan tahun 2020 analisis ini pada prinsipnya menggunakan ilmu pengindraan jauh intrepetasi citra menggunakan software ENVI 5.1 sebagai alat untuk analisis data citra.

\subsubsection{Overlay Peta}

Tenik overlay peta merupakan sebuah langkah tumpang susun dua atau lebih peta tematik untuk memperoleh informasi baru. Dilakukan overlay peta tutupan lahan tahun 2020 dengan peta fungsi kawasan hutan dari Kementrian Lingkungan Hidup dan Kehutanan tahun 2013 untuk mendapatkan peta alih fungsi lahan yang tidak sesuai dengan fungsi kawasan hutan.

\subsubsection{Analisis Kernel Density}

Kernel Density Merupakan analisis fungsi statistik yang dikembangkan kedalam fungsi spasial untuk mengukur persebaran intesitas suatu titik pada radius tertentu. Kernel density adalah model spasial perhitungan untuk mengukur kerapatan suatu titik secara non parametrik. secara konsep kondisi suatu titik yang rapat dan center suatu titik memiliki intensitas zona yang tinggi dan menurun seiring menjauh dari titik center (Burt J.E, Barber M.G, Rigby D.L, 2009). Tahapanya kernel density mencari nilai $\mathrm{K}$, melihat jarak antara titik a titik $\mathrm{x}$ dan setiap nilai data adalah banyak data $h$. Karena h adalah unit yang sama sebagai x sebagai rasio dimensionless. Skala jarak ini digunakan dalam fungsi kernel density untuk menemukan kontribusi setiap titik pengamatan. Dengan nilai $\mathrm{K}$ sebuah fungsi penurunan dari setiap jarak, kontribusi dan pengamatan jauh dari nilai $\mathrm{x}$ akan menjadi kecil, dimana kedekatan pengamatan akan berkontribusi lebih. Dalam proses ini analisis kernel density dilakukan dengan perangkat Sistem informasi geografis (SIG).

\subsubsection{Analisis Deskriptif}

Teknik analisis ini digunakan untuk menjelaskan bagaimana hubungan kompleks antara ruang yang mana mencakup kejadian perubahan penggunaan lahan dengan konflik satwa liar harimau Sumatra. Dengan analisis deskriptif ini hasil dari analisis data sebelumnya dapat diintrepetasi dan dideskripsikan atau menggambarkan data yang telah diperoleh ini tidak bermaksud membuat kesimpulan yang berlaku untuk umum atau generalisasi. 


\section{HASIL DAN PEMBAHASAN}

\section{Hasil}

Dinamika tutupan lahan menekan habitat satwa dan terputusnya konektivitas habitat. Seringkali setiap terjadi kejadian konflik antara harimau dan manusia, hewan ini selalu yang menjadi faktor dianggap penyebab konflik. Pada wilayah Kabupaten Pesisir Selatan secara umum bersinggungan langsung dengan kawasan hutan yang berfungsi sebagai hutan lindung dan hutan konservasi yang didominasi oleh lanskap hutan yang menjadi habitat Harimau Sumatera. Beberapa area pada kawasan transisi antara hutan dan perkebunan telah sering terjadi konflik harimau. Pemanfaatan dan Penenjukanstatus kawasan diatur dalam surat Keputusan Menteri Lingkungan Hidup dan Kehutanan no 35 tahun 2013.

Dari hasil analisis data dalam kawasan hutan ini banyak terdapatnya alih fungsi lahan dimana kawasan yang harus dijadikan kawasan lindung di alih fungsikan menjadi lahan pertanian, sawah, dan perkebunan hal ini dapat menimbulkan deforestasi hutan sehingga teradinya fragmentasi lanskap hutan dan penekanan habitat satwa. Alih fungsi ini sebetulnya merupakan pelanggaran yang tidak mengikuti regulasi yang ada di Indonesia. Kami menemukan banyaknya spot-spot area yang tidak sesuai dengan peruntukan kawasan hutan, ketidak sesuain ini tentunya akan berdampak juga untuk keberlangsungan kehidupan alami. Lebih lanjut ditemukan bahwasanya ada empat kategori pemanfaatan lahan yang tidak sesuai dengan fungsi kawasan hutan, kususnya kawasan lindung, kawasan suaka alam, kawasan pelestarian alam dan Taman Nasional Kerinci Seblat. Selanjutnya distrbusi spasial ketidak sesuaian pemanfaatan lahan pada kawasan hutan dapat dilihat pada peta Gambar 2, dimana ditemukan bahwa alih fungsi lahan berada pada kawasan Taman Nasional Kerinci Seblat, Hutan Lindung dan Suaka Margasatwa Tarusan Arau Hilir dimana kawasan tersebut dalam SK 35 KLHK tentang fungsi kawasan hutan dijadikan kawasan konservasi namun dialih fungsikan ke lahan pertanian, sawah, lahan terbuka, dan perkebunan.

Gambar 2. Peta perbandingan pemanfaatan penggunaan lahan eksisting dengan rencana kawasan hutan di Kabupaten Pesisir Selatan

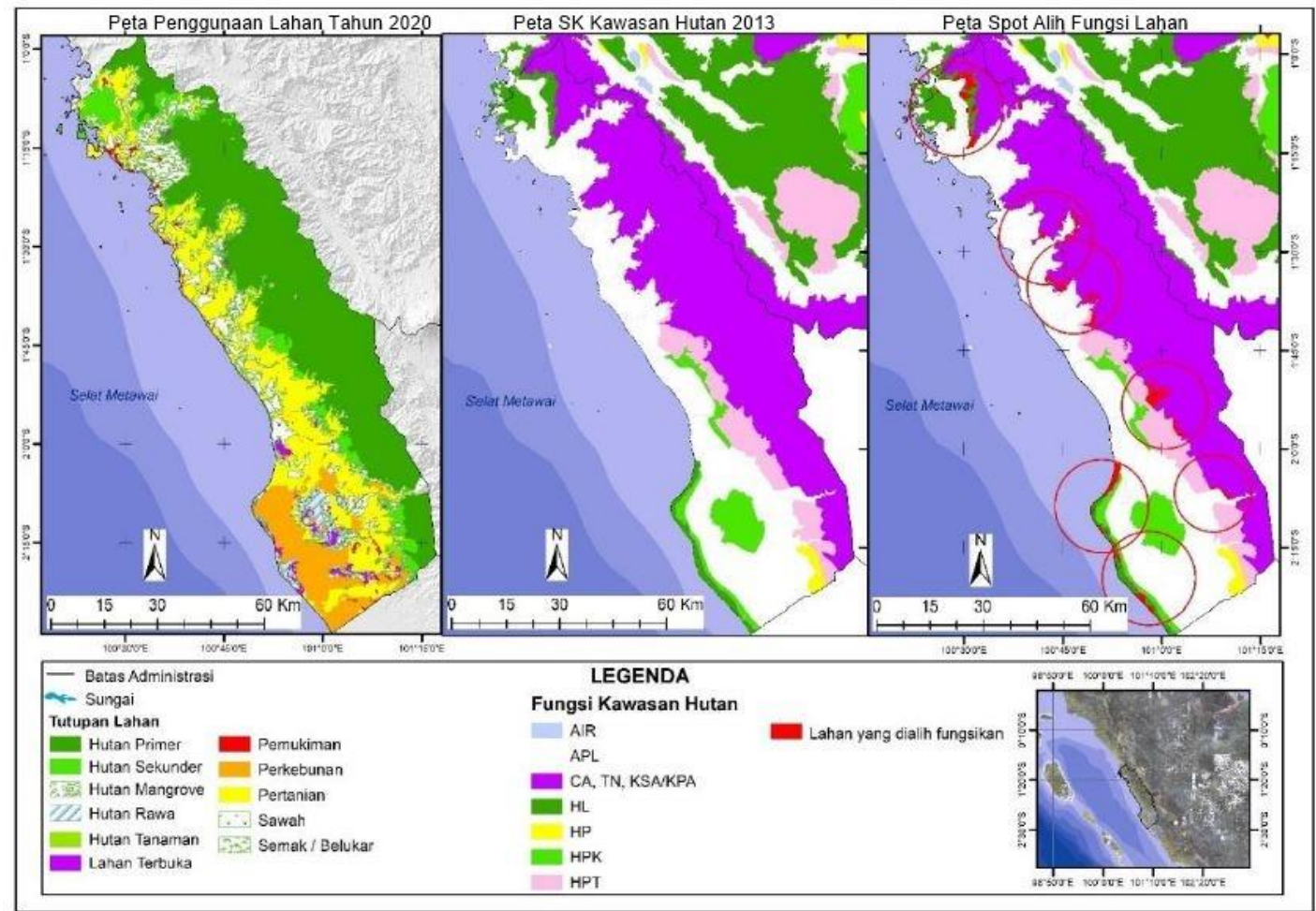


Lahan yang dialih fungsikan seluas $16.299 \mathrm{Ha}$ dari semua fungsi kawasan lindung pada tahun 2020. Terlihat pada gambar 5 peta c lingkaran dan area berwarna merah menunjukkan area yang dialihfungsikan menjadi lahan agrikultur di bawah ini tabel lahan yang dialihfungsikan:

Gambar 3. Chart eksisting landskap pada Kawasan Hutan

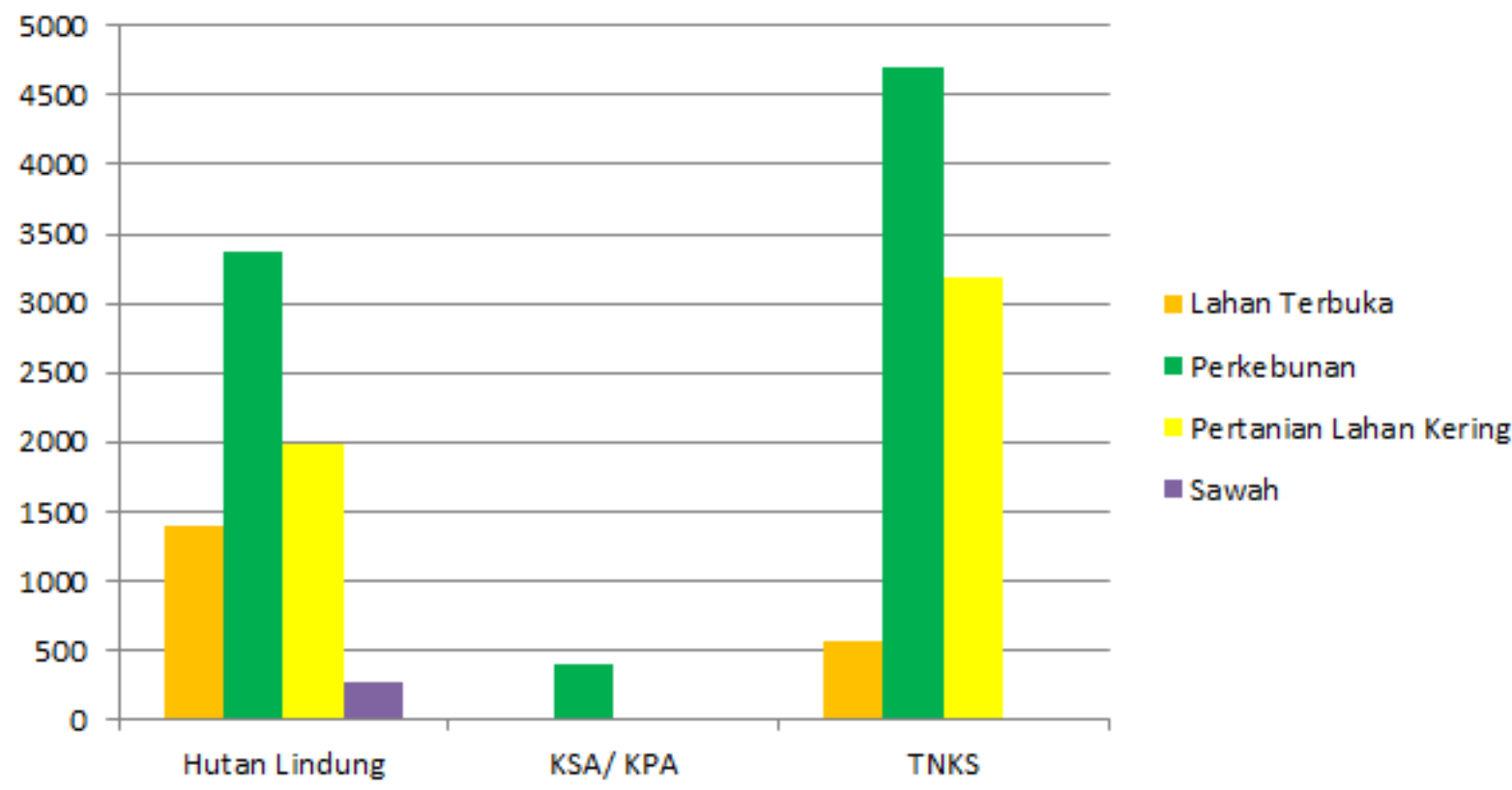

Sering terjadinya alih fungsi lahan yang memicu terjadinya konflik satwa, salah satu konflik satwa adalah konflik Harimau Sumatera yang merugikan masyarakat serta satwa yang terkena konflik hal ini terjadi karena tertekannya habitat alami Harimau Sumatera yaitu tutupan lahan hutan. Dari tabel diatas dapat dijelaskan fungsi kawasan yang telah dialihfungsikan, Kawasan hutan lindung telah dialihfungsikan seluas $7.031 \mathrm{Ha}$, kawasan suaka alam $409 \mathrm{Ha}$ dan Taman Nasional Kerinci Seblat 8.858.

Sering terjadinya alih fungsi lahan yang memicu terjadinya konflik satwa, salah satu konflik satwa adalah konflik Harimau Sumatera yang merugikan masyarakat serta satwa yang terkena konflik hal ini terjadi karena tertekannya habitat alami Harimau Sumatera yaitu tutupan lahan hutan. Dari tabel diatas dapat dijelaskan fungsi kawasan yang telah dialihfungsikan, Kawasan hutan lindung telah dialihfungsikan seluas $7.031 \mathrm{Ha}$, kawasan suaka alam $409 \mathrm{Ha}$ dan Taman Nasional Kerinci Seblat 8.858.

Dari data riwayat kasus konflik satwa terdapat 23 kasus riwayat konflik harimau sumatera yang tercatat dari tahun 2005-2016 oleh BKSDA Provinsi Sumatera Barat, kasus konflik terbanyak terdapat di Nagari Siguntur Kecamatan XI Tarusan Kabupaten Pesisir Selatan tercatat 6 jumlah kasus konflik 4 kasus tahun 2010. Satu kali kejadian kasus tahun 2008, dan satu kasus pada tahun 2011 kasus konflik paling sedikit berada di Nagari Batang Kapeh, Koto Ranah dan Jorong Cumantih tercatat 1 kejadian konflik dalam kurun waktu 10 tahun terakhir. Data kasus kejadian konflik Harimau ini dikembangkan dalam analisis lebih lanjut pada analisis spasial kernel density. 
Gambar 4. a) Peta Tutupan Lahan 2020, b) Peta Zona Bahaya Konflik Harimau Sumatera.

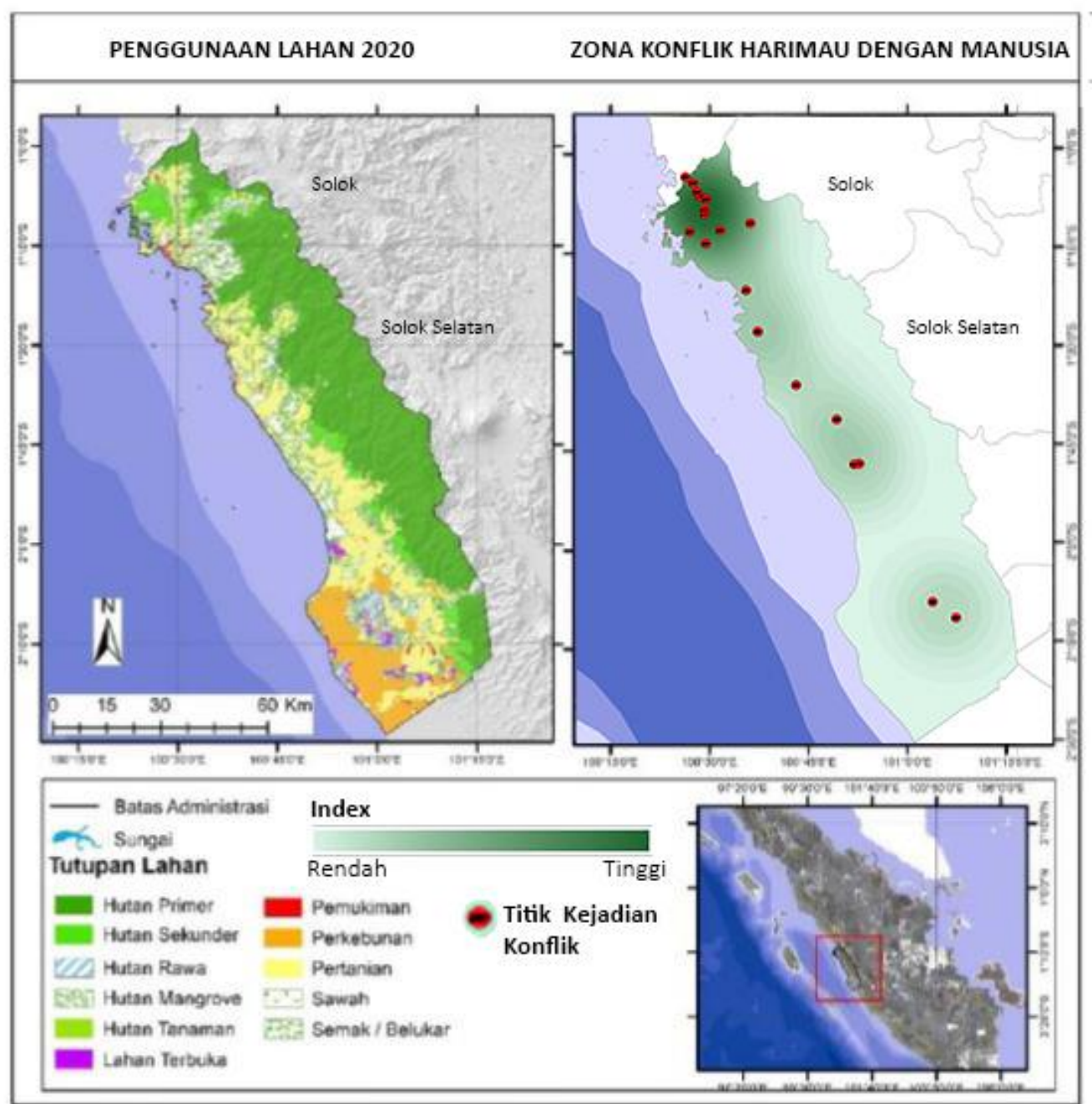

Berdasarkan peta zonasi konflik, bahaya yang paling tinggi berada pada zona hijau gelap pada zona ini berkemungkinan besar terjadinya kasus yang berulang pada lokasi yang sama seiring menjauhnya jarak dari sumber lokasi kejadian konflik tingkatan bahaya konflik menurun zona berwarna hijau pudar kategori bahaya sedang dan zona bahaya rendah pada zona berwarna hijau. Area dengan tingkat bahaya konflik tinggi yang berada di Kecamatan XI Tarusan, penyebab terjadinya konflik terputusnya konektivitas habitat hutan yang menjadi habitat alami Harimau Sumatera. Secara alami hewan memiliki batas teritorial kawasannya untuk masing masing kelompok, walaupun kondisi habitat telah dirubah oleh manusia menjadi pemanfaatan lain hewan tersebut tetap mengklaim wilayah itu masih kawasannya. Sehingga saat terjadi perburuan oleh satwa dalam mencari makanan, harimau berani turun ke kampung warga dan menyerang ternak.

\section{Pembahasan}

Banyak faktor penyebab konflik satwa liar dengan manusia diantaranya kompetisi pemanfaatan ruang antara manusia dengan wilayah jelajah satwa, tidak mampunya suatu landskap menampung jumlah populasi yang menjadi habitat untuk memenuhi kebutuhan home range satwa (Hanif et al. 2021). Terjadinya fragmentasi landskap hutan juga mendorong terjadinya konflik karena landskap alami sudah diisi oleh kawasan antropogenik sehingga terjadinya singgungan wilayah jelajah satwa pada landskap budidaya tersebut (Rahman, 2021). Ketika lanskap hutan rusak tidak mampu menyuplai kebutuhan hidup mereka maka hewan akan mencari alternative dengan bergerak menuju batas tepi hutan dan memasuki lahan pertanian ataupun permukiman warga 
(Hanif et al. 2021). Sebagai hewan pemangsa utama (top predator), harimau memerlukan wilayah habitat yang luas supaya dapat hidup dan berkembang biak. Oleh karena itu, kepadatan hewan mangsa sebagai sumber pakan merupakan faktor yang sangat penting dalam mendukung keberlanjutan populasi harimau (World Wildlife Fund, 2010).Wilayah jelajah untuk seekor harimau betina adalah sekitar $20 \mathrm{~km} 2$, sedangkan untuk harimau jantan sekitar 60-100 km2 (Winarno, Djoko Gunardi, 2009).

Pola distribusi spasial kejadian konflik harimau dengan manusia berbentuk spot pada wilayah utara Kabupaten Pesisir Selatan, pada wilayah itu terjadi alih fungsi lahan dari landskap hutan menjadi pemanfaatan lainnya, tidak hanya itu pada wilayah tersebut juga terdapat dua kelompok landskap hutan alami yang terpisah oleh pedesaan dengan penutup lahan terbangun. Ini membuktikan secara geografis dan kondisi lingkungan wilayah utara ini memang cenderung terjadinya konflik satwa liar. Konflik Harimau Sumatera selalu berada pada area batas tepi hutan (forest edge) antara tutupan lahan hutan dan lahan pertanian yang bersinggungan langsung dengan aktivitas manusia karena terputusnya konektivitas antar habitat Harimau Sumatera. Pemetaan zona bahaya konflik menjadi salah satu cara untuk memberikan peringatan dini bagi masyarakat agar lebih siaga dan berhati-hati pada zona konflik bahaya yang tinggi agar bisa mencegah terjadinya konflik yang berlanjut dan mencegah punahnya Harimau Sumatera. Dari hasil penelitian ini dapat ditentukannya suatu area yang perlu untuk diawasi dan diberi rambu peringatan zona rawan konflik Harimau Sumatera pada zona rawan konflik yang tinggi.

Penanganan lebih lanjut terhadap kasus Harimau Sumatera yakni dengan dilakukannya pemasangan perangkap dilokasi konflik dan rehabilitasi Harimau Sumatera yang tertangkap. Sangat diperlukannya tindakan intensif untuk mencegah terjadinya kasus konflik yang berkepanjangan yang bisa memberikan dampak negatif bagi manusia maupun bagi Harimau Sumatera yang memicu kepunahan bagi satwa ini. Langkah tindakan sosial seperti mengembalikan local wisdom atau kearifan lokal masyarakat terhadap satwa Harimau juga perlu ditingkatkan, karena kultur masyarakat Sumatera Barat yang sangat menghormati satwa ini yang dianggap sebagai warisan leluhur yang telah tercantum dalam berbagai kultur Minang salah satunya seperti silek. Dengan mengmbalikan kearifan lokal masyarakat yang hidup berdampingan dengan satwa liar ini akan menjadikan langkah dimana kegiatan sosial dan perekonomian masyarakat tetap dapat berlangsung tanpa harus merugikan salah satu pihak. Penyadaran kearifan lokal dengan hidup berdampingan dengan satwa liar tentunya tidaklah mudah. Akan tetapi ini dapat dilakukan secara bertahap seperti yang telah dilakukan oleh WWF pada Negara seperti India dengan melakukan pengandangan hewan ternak yang aman dari serangan Harimau hingga menekan alih fungsi lahan hutan sehingga habitat satwa liar tidak terganggu dan kelestrian lingkungan juga terjaga.

\section{KESIMPULAN}

Secara keseluruhan pemanfaatan lahan yang tidak sesuai dengan penunjukkan kawasan hutan dimana yang seharusnya ditutupi oleh landskap hutan akan tetapi pemanfaatanya adalah pertanian lahan kering. Pada kawasan hutan lindung HL luas perkebunan mencapai 3.363 hektar, pada Kawasan Suaka Alam KSA 403 hektar dan pada kawasan TNKS Taman Nasional Kerinci Seblat 3192 Hektar. Dalam kurun waktu satu dekade terjadi 23 kali kejadian konflik harimau dengan manusia. Secara spasial konflik ini terfokus pada wilayah utara Kabupaten Pesisir Selatan, dimana tersebar diantara dua landskap hutan yang terpisah.

Terjadinya ketidak sesuaian pemanfaatan lahan eksisting dengan rencana kawasan hutan yang telah ditetapkan oleh Kementrian Kehutanan, penyimpangan pemanfaatan lahan ini cenderung terjadi pada kawasan perbatasan antara kawasan APL arahan pemanfaatan lainnya dengan kawasan hutan. Hasil analisis konflik pada Kecamatan XI Tarusan merupakan zona dengan tingkat kerawanan yang paling tinggi karena sering terjadinya konflik yang berkelanjutan di daerah tersebut. konflik yang berlanjut dapat menyebabkan kepunahan satwa Harimau Sumatera dan mengganggu keseimbangan ekosistem di hutan sumatera. Hidup berdampingan dengan satwa liar 
dengan menjunjung tinggi kearifan lokal dalam pemanfaatan lahan yang sesuai dengan peruntukan perlu dilakukan untuk mengurangi konflik. Pemetaan zona bahaya konflik adalah salah satu cara untuk memberikan peringatan dini bagi masyarakat agar lebih siaga dan berhatihati pada zona konflik bahaya yang tinggi agar bisa mencagah terjadinya konflik yang berlanjut dan mencegah punahnya harimau sumatera dari habitatnya.

\section{PENGHARGAAN}

Ucapan terima kasih penulis sampaikan kepada tim yang telah membantu penulis untuk menyelesaikan penelitian ini sampai selesai, dan penulis ucapkan terima kasih kepada BKSDA Provinsi Sumatera Barat yang telah bersedia memberikan data yang dibutuhkan penulis dalam membuat penelitian ini.

\section{REFERENSI}

BurtJ.E, BarberM.G, RigbyD. L, 2009. Elementary Statistics for Geographers. Guilford. Press A Division of Guil ford Publications, Inc.72 SpringStreet,NewYork,NY.

Balai Konservasi Sumber Daya Alam. Data Konflik Satwa. Provinsi Sumatera Barat. Kota Padang.

Danoedoro, Projo. 2012. Pengantar Pengindraan Jauh Digital. ANDI. Yogyakarta.

Ganesa, Ari, Aunorohim. 2012. Perilaku Harian Harimau Sumatera Panthera Tigris Sumatrae Dalam Konservasi Ex-situ Kebun Binatang Surabaya. FMIPA Jurusan Biologi. Jurnal Sains dan Seni ITS. Vol 1 no 1. Surabaya.

Hanif $M$ and Nofrizal A Y, 2017. Investigation Natural Forest Ecosystem Use High Resolution and Lidar Data. Journal Environment and Earth Science IIESTE. Vol 9.

Hanif M, et al, (2020). Multi Spectral Satellite Data to Investigate Land Expansion and Related Micro Climate Change as Threats to the Environment. Journal IOP Conference Series: Earth Environ. Sci., Available at: https://iopscience.iop.org/article/10.1088/17 55-1315/303/1/012030.

Hanif M, Hidayat A R, Rahman H, Wibisono H, Nazar H A, Ahyuni, Ratna Wilis. 2021. Zonation of Conflict between Sun Bear (Helarctos Malayanus)-Human as an Effort Wildlife Conflict Mitigation. MAT Journal Environmental Engineering and Studies eISSN: 2582-3132. Volume-6, Issue-2 (May-August, 2021).

Hanif M. Rahman H, Hidayat A R \& Wibisono H T. 2020. Spatial Assessment of Potential Conflict of Sun Bear- Human Based on Landscape Ecology in Pasaman. Preprint ORG. doi:10.20944/preprints202008.0498.v1

Hidayat Atthoriq Rizki, Febriani Natasyah. 2021. Pemodelan Probabilitas Sebaran Habitat Untuk Menetukan Kawasan Prioritas Konservasi Burung Rangkong Gading (Rhinoplax Vigil) Di Geopark Silokek, Kabupaten Sijunjung. Jurnal Konservasi Hayati, 17 (1): 35-43, April. e-ISSN: 2722-1113. https://ejournal.unib.ac.id/ index.php/hayati/

Hidayat A R et, al. 2020. Modeling of Conservation Priority Zone for the Helmeted Hornbill (Rhinoplax Vigil) In Silokek Geopark Area, West Sumatra. Preprints. DOI 10.20944/preprints202009.0676.v1

Hidayat A R and Hanif M. 2020. Spatial Modeling of the Threat of Damage to the Peatland Ecosystem in the Mainland of Bengkalis Regency, Riau Province. Journal Social Polites. Vol 20. Special Issue. No 2. doi: 10.33541/sp.v21i3.2249 
Oliviana, Kelama Evine. 2011. Pendugaan Populasi Harimau Sumatera Panthera Tigris Sumatrae, Pocock 1929 Menggunakan Metode Kamera Jebakan Di Taman Nasional Berbak. Skripsi. IPB. Bogor.

PurwantiRenita,BudisusantoYanto.Studi BatasWilayahMenggunakanMetode Kartometrik. Studi Kasus: Kecamatan Sukolilo, KotaSurabaya. JurnalIlmiah Geomatika Volume21 No. 1 Agustus2015: 25-30.

Rahman Henzulkifli. 2021. Analisis Spasial Perubahan Struktur Lanskap dan Konektivitas Lanskap Ekosistem di Kabupaten Padang Pariaman. Skripsi Geografi. Repositori Universitas Negeri Padang.

Rahman H, Triyatno, Hanif M, Indrayani P. 2020. Spatial Assessment of Landscape Structure Changes and Ecological Connectivity in Padang Pariaman. Journal of Remote Sensing GIS and Technology, 6(2). Available at: https://www.researchgate. net/publication/342707817_Spatial_Assessm

ent_of_Landscape_Structure_Changes_and_Ecological_Connectivity_in_Pariaman.

SK 35/II/2013. Kementrian Kehutanan. Penujukkan Status KawasanHutan.

Soehartono. 2007. Strategi Dan Rencana Aksi Konservasi Harimau Sumatera. Departemen Kehutanan.

World Wildlife Fund. 2012. Harimau Sumatera Panthera Tigris Sumatrae. www.wwf.or.id. Jakarta.

World Wildlife Fund. 2010. WWF'S Work On Sumatran Tiger Conservation. Kawasan Mega Kuningan Jakarta.

Winarno, Djoko Gunardi \& Ameliya, Revi. 2009. Pendugaan Populasi Harimau Sumatera dan Satwa Mangsanya di Taman Nasional Bukit Barisan Selatan. Jurnal Bioesfera. Lampung. 